\title{
The emergence of Wikipedia as a new media institution
}

\author{
Kim Osman \\ Queensland University of Technology \\ Z1-515 Musk Ave, Kelvin Grove \\ Queensland, 4059, Australia \\ +61731388007 \\ kim.osman@qut.edu.au
}

\begin{abstract}
Wikipedia is an important institution and part of the new media landscape having evolved from the collaborative efforts of millions of distributed users. This poster will present ongoing research that examines how the issues that have been highlighted by conflict within the community have shaped the evolution of Wikipedia from an open wiki experiment to a global knowledge producer. Bringing together the concepts of interpretive flexibility and generative friction with existing theories on the evolution of institutions, the research aims to present possible futures for Wikipedia as part of not only the larger Wikimedia movement, but of an open and accessible web.
\end{abstract}

\section{Categories and Subject Descriptors}

K.2 [History of Computing]: Theory. K.4.3 [Computers and society]: Organizational Impacts - Computer-supported collaborative work.

\section{General Terms}

Economics, Human Factors, Theory.

\section{Keywords}

Institutionalism, Wikipedia, interpretive flexibility, internet history.

\section{INTRODUCTION}

This research brings together existing scholarship on Wikipedia as a successful open community together with more critical accounts of diversity in open communities. Using controversy as a heuristic device, the research examines how issues that have been highlighted by conflict within the community have shaped the evolution of Wikipedia.

A significant and important case study, Wikipedia is the only nonprofit among the top sites on the internet, and has kept its business model that embodies Enlightenment ideals the early web "hacker" ideals of freedom, openness and access to information and resources - yet it is currently struggling with diversity [1] and participation [2] in an increasingly commercial digital media environment among the likes of Facebook, Twitter and YouTube. The poster will present preliminary findings from a historical discourse analysis of identified controversies in Wikipedia's

Permission to make digital or hard copies of all or part of this work for personal or classroom use is granted without fee provided that copies are not made or distributed for profit or commercial advantage and that copies bear this notice and the full citation on the first page. To copy otherwise, or republish, to post on servers or to redistribute to lists, requires prior specific permission and/or a fee.

WikiSym '13, August 05 - 07 2013, Hong Kong, China

Copyright is held by the owner/author(s). Publication rights licensed to ACM. ACM 978-1-4503-1852-5/13/08_..\$15.00. history, along with an analysis of current issues that are relevant to the community using the following framework.

\section{THEORETICAL FRAMEWORK}

In order to address the issues surrounding Wikipedia's sustainability I will bring together the concepts of interpretive flexibility [3], generative friction [4], and theories from institutional economics to explore the history of Wikipedia. In combining these approaches, I hope to give an account of how change occurs when an open community develops in an online space. I will examine how Wikipedia has evolved, how moments of controversy have shaped the encyclopedia, and how this change is a combination of social agency and technology. Indeed, the internet and its platforms (while innovative) aren't revolutionary at all, they are the result of social choices over time, that at any point could have been used or defined differently resulting in different products and practices to what we know today.

\subsection{Interpretive flexibility}

Taking into account that "the 'successful' stages in the development are not the only possible ones" [3], interpretive flexibility suggests that there is a period at the beginning of a technology's existence where meaning is still being negotiated and it is open to multiple interpretations by relevant stakeholders [5]. In science, this flexibility "soon disappears" as consensus emerges [3]. What this period is, and how soon it ends in relation to digital technologies is still relatively unknown due to the lack of research on the interpretive flexibility of online platforms.

Additionally, the role of technology in the social construction of an artefact has often been sidelined, and this research is important as it will recognize not only the shaping effects of the various technologies that are actors in Wikipedia, but also the role of its non-profit business model, which "few researchers recognize ... as a relevant non-human actor in the process of social construction" [5].

I will therefore be looking at how Wikipedia emerged from the interests of its user groups at particular stages of its development. Using moments of controversy as a heuristic device, I will look at how these conflicts highlight the value and meaning assigned to Wikipedia by different social groups. As [3] state, "Controversies offer a methodological advantage in the comparative ease with which they reveal... interpretative flexibility." For controversies are not isolated units, but "parts of wider, evolving structures [and] they are essential to the progress of scientific knowledge and philosophical understanding" [6]. Controversies also help in tracing historical events and recognizing when new meanings are generated by the discussion around controversial issues [7]. 


\subsection{Institutionalism}

If the reasons behind concerns about participation in Wikipedia are to be understood, we also need to understand the process of change, and how exactly the rules that have been formed by the community are creating barriers to entry for new users. For it is not the case that the open hacker ethos that created Wikipedia precludes it from being subject to processes of institutionalism - it is not an either/or scenario. There are other factors to be considered that will influence what is happening in Wikipedia and how this period in its development is managed.

Wikipedia has been chosen as a case study precisely because it is open. It held all the ideals of an open, accessible democratic, egalitarian web. Through a historical account and analysis we can see how these claims have played out. And as [8] note, "Power and interests have been slighted topics in institutional analysis." Institutionalism, where rules and norms structure political, economic and social interaction [9], provides an additional lens through which to examine this process of change, and how the struggle to achieve closure and stability in meaning has occurred.

\subsection{Generative friction}

In Wikipedia, conflict and the friction created when multiple viewpoints come together has created a variety of rules and norms for the community. These rules regulate the editorial process to produce high quality content [10], and this research therefore frames conflict as a generative friction, where diversity results in increased innovation as differing views overlap. This in turn prompts better coordinating mechanisms and therefore "dissonance contributes to organizational learning and economic evolution" [4]. Where and in what context dissonance stops being productive and actually starts to hinder the progress of Wikipedia is future research for this project.

\section{HISTORIOGRAPHY}

Tracing the history of the platform from its early DIY and counterculture roots, through the heuristic device of controversies, to its possible futures as an open and non-profit institution, will shed light on how institutions emerge and evolve in a new media environment. Moreover, "Reconstructing interpretative flexibility while the technology is still in flux - and thus open to maneuvering - may give rise to new perspectives on how power relationships transpire in a networked environment" [5]. Wikipedia is the ideal site to study these questions of power, as it is where, "we can learn whether the Internet facilitates increased open participation across cultures, or reinforces existing global hierarchies and entrenched power dynamics" [11]. The research will investigate relationships among different actors in Wikipedia's sociotechnical system and examine how barriers to entry in an open community are formed and maintained. It is also important to develop contemporary media theories as we study these "practices and power" of digital media [12],

By considering relevant actors in Wikipedia's history and not relying on versions (e.g. Web 2.0) that are currently the prevailing approach to writing internet histories [13], this research will present a non-teleological account of the evolution of Wikipedia. It will combine a historical discourse analysis with interviews from key informants and will add to existing digital media scholarship where, David M. Berry says, “'more hack less yack' has been interpreted as lack of critical engagement and [a] move away from theoretical concerns" [14]. The research will also consider the representation of Wikipedia in different forums and how conversations about specific controversies and events (for example the gender gap, paid editing) move between these spaces.
By examining the issues of participation, regulation and sustainability in relation to controversies in Wikipedia, this research will examine how inclusion and diversity play out in a mainstream open community and a new media institution.

\section{REFERENCES}

[1] Wikimedia Foundation. 2011. Wikipedia editors study: Results from the editor survey, April 2011. http://upload. wikimedia.org/wikipedia/commons/7/76/Editor_Survey_Rep ort_-_April_2011.pdf.

[2] Suh, B., Convertino, G., Chi, E. H. \& Pirolli, P. 2009. The singularity is not near: The slowing growth of Wikipedia. In Proceedings from WikiSym'09, 2009 International Symposium on Wikis (Orlando, Florida, U.S.A, October 2527, 2009) ACM, New York, NY, Article 8. DOI= http://doi.acm.org/10.1145/1641309.1641322.

[3] Pinch, T. \& Bijker, W. 1984. The social construction of facts and artefacts: or how the sociology of science and the sociology of technology might benefit each other. Social studies of science, 14(3), 399-441.

[4] Stark, D. 2009. The Sense of Dissonance. Princeton, New Jersey: Princeton University Press.

[5] Van Dijck, J. 2011. Tracing Twitter: The rise of a microblogging platform. International Journal of Media \& Cultural Politics, 7(3), 333-348. DOI $=10.1386 /$ macp.7.3.333.

[6] Nudler, O. 2011. Introduction. In O. Nudler (Ed.), Controversy Spaces (pp. 1-6). Amsterdam: John Benjamins Publishing Company.

[7] Naishtat, F. 2011. Historiographic refocalization and change in the historicity regime. In O. Nudler (Ed.), Controversy Spaces. Amsterdam: John Benjamins Publishing Company.

[8] DiMaggio, P. \& Powell, W. 1991. The new institutionalism in organizational analysis. http://www.stanford.edu/ $\sim$ woodyp/papers/dimaggioandpowell_intro.pdf

[9] North, D. 1991. Institutions. Journal of Economic Perspectives, 5(1), 97-112.

[10] Casebourne, I., Davies, C., Fernandes, M. \& Norman, N. 2012. Assessing the accuracy and quality of Wikipedia entries compared to popular online encyclopaedias: A comparative preliminary study across disciplines in English, Spanish and Arabic. Epic, Brighton, UK.

http://commons.wikimedia.org/ wiki/File:EPIC_Oxford_report.pdf

[11] Graham, M. 2012. Who represents the Arab world online? Mapping and measuring local knowledge production and representation in the Middle East and North Africa. http://www.oii.ox.ac.uk/ research/projects/?id=70.

[12] Horst, H., Hjorth, L. \& Tacchi, J. 2012. Rethinking ethnography: An introduction. Media International Australia, (145), 86-93.

[13] Allen, M. 2012. What was Web 2.0? Versions as the dominant mode of internet history. New Media \& Society, (July), 1-16. DOI=10.1177/1461444812451567

[14] Prescott, A. (@Ajprescott). 2013.@berrydm notes that 'more hack less yack' has been interpreted as lack of critical engagement and move away from theoretical concerns. January 18, 2013, 3:40am. Tweet. 
